\title{
A MECHANISM FOR THE EROSION OF EB PVD TBCS
}

\author{
R.G Wellman and J.R Nicholls \\ Cranfield University, Cranfield, Bedford, MK 43 OAL UK
}

\section{Keywords: Erosion, Thermal Barrier Coatings, Modelling, Erosion Mechanisms}

\begin{abstract}
Since the introduction of electron beam (EB) physical vapour deposition (PVD) TBCs and their application to moving components in the hot gas stream, erosion has become a prime concern. This project has been involved in determining the erosion mechanism of EB PVD TBCs, in order to develop a computational erosion model. The unique columnar microstructure of the EB PVD TBCs precludes the use of the classical brittle erosion mechanisms. This meant that a thorough investigation into the erosion mechanism of the coatings was necessary before it would be possible to develop a model to predict material wastage.
\end{abstract}

This paper looks at the erosion of EB PVD TBCs and discusses the type of damage caused by erosion as well as proposing a mechanism of erosion. It was found that in all cases the erosion of the coatings proceeds through the accumulation of damage in the form of horizontal cracks in the columns of the coating and subsequent removal of the fractured sections.

\section{INTRODUCTION AND REVIEW OF 'THE STATE OF THE ART'}

There has been a limited amount of published work on the erosion of TBCs, with a number of the papers reporting only normalised erosion rates. Most of the papers on TBCs are more concerned with the thermal cyclic life of the coatings [1-4], the processing of the coatings [5-7] or the thermal conductivity of the coatings [8;9]. This is because throughout the development of TBCs the primary life limiting factor of the coating system has been the stress generated during thermal cycling. This stress is a result of the thermal expansion mismatch between the ceramic topcoat and the substrate, and the oxide growth at the interface. Erosion of the component was never considered a primary life-limiting factor, and all life prediction models to date are concerned only with the thermal properties and not with erosion. This is understandable, as in the early years of TBCs, owing to the regions in which they were used, erosion was not a major concern. In burner cans, for example, any erosion will occur at low impact angles, and ceramics exhibit maximum erosion at high impact angles. The use of TBCs on the vane airfoil surface leads to a certain degree of erosion due to the higher impact velocities, however with the application of TBCs on rotating airfoils the problem of erosion becomes much more severe. Of the papers, on erosion only a few $[10 ; 11]$ touch on the actual erosion mechanism as opposed to merely reporting the measured erosion rates [12-14].

There are however, a few important points that can be noted from the literature. Both the PS and the EB-PVD coatings exhibit a variation in the extent of brittle response to erosion with impact angle at room temperature. There is also consensus on the fact that the PS coatings have an erosion rate almost an order of magnitude greater that the EB-PVD coatings. The erosion rates of the coatings increases with increasing particle velocity, but had a velocity exponent of only 1-2, where for bulk ceramics the exponent will be in the region of 2-4.

Previous studies of brittle erosion have shown that material removal occurs via the formation and intersection of cracks [15-17]. However, in EB PVD TBCs, due to the columnar microstructures, 
these cracks do not intersect with each other or indeed with the top surface. Previous work conducted at Cranfield University [10;18;19] has shown that there are a number of distinct mechanisms by which TBCs erode. These depend primarily on three factors, namely particle size (erosion or foreign object damage), particle temperature (is the impacting particle, solid or in a semi-molten state i.e. 'pasty') and microstructure (the important point being whether the coating is an EB PVD or a PS TBC). From the micrographs in the literature, it appears as though the cracks do not propagate into neighbouring columns during the erosion of EB PVD coatings. Further, the cracks are all perpendicular to the direction of column growth, and no mention is made in the literature as to the mechanism by which these cracks form, other than to say that they are the result of particle impact.

The erosion rate of EB-PVD coatings does not appear to be greatly affected by increases in temperature, while the PS coatings show a rapid increase in erosion rate with increase in temperature from $600-800^{\circ} \mathrm{C}$. The exception to this occurs when using an erodent that softens and becomes "pasty" at the temperature being tested, when higher erosion rates can occur due to pull out of fractured sections of the coating by the impacting particle on rebound [10].

\begin{tabular}{|c|c|c|c|c|c|c|c|}
\hline Ceramic & $\begin{array}{l}\text { Production } \\
\text { Route }\end{array}$ & $\begin{array}{l}\text { Test } \\
\text { Temp } \\
\left({ }^{\circ} \mathrm{C}\right) \\
\end{array}$ & $\begin{array}{l}\text { Test } \\
\text { Velocity } \\
(\mathrm{m} / \mathrm{s})\end{array}$ & Erodent & $\begin{array}{l}\text { Impact } \\
\text { Angle } \\
\left({ }^{\circ}\right)\end{array}$ & $\begin{array}{l}\text { Erosion } \\
\text { Rate } \\
(\mathrm{g} / \mathrm{kg})\end{array}$ & Ref. \\
\hline $\mathrm{ZrO}_{2}-8 \mathrm{wt} \% \mathrm{Y}_{2} \mathrm{O}_{3}$ & PS & $1250-1600$ & $260-320$ & $130 \mu \mathrm{m} \mathrm{Al} \mathrm{Al}_{2}$ & $20-90$ & $15-46$ & [20] \\
\hline $\mathrm{ZrO}_{2}-20 \mathrm{wt} \% \mathrm{Y}_{2} \mathrm{O}_{3}$ & EB-PVD & RT & 30 & $63-130 \mu \mathrm{m} \mathrm{Si0} 0_{2}$ & 30,90 & $0.12-0.16$ & [14] \\
\hline $\mathrm{ZrO}_{2}-8 \mathrm{wt} \% \mathrm{Y}_{2} \mathrm{O}_{3}$ & PS & RT & 30 & $63-130 \mu \mathrm{m} \mathrm{Si0} 0_{2}$ & 30,90 & $0.13-0.36$ & [14] \\
\hline $\mathrm{ZrO}_{2}$-ceramic & PS & 1300 & 244 & $27 \mu \mathrm{m} \mathrm{Al}{ }_{2} \mathrm{O}_{3}$ & 15 & $4-163$ & [21] \\
\hline $\mathrm{ZrO}_{2}-8 \mathrm{wt} \% \mathrm{Y}_{2} \mathrm{O}_{3}$ & EB-PVD & $260-815$ & $122-305$ & $8-130 \mu \mathrm{m} \mathrm{Al}{ }_{2} \mathrm{O}_{3}$ & $20-90$ & Relative & [22] \\
\hline $\mathrm{ZrO}_{2}-8 \mathrm{wt} \% \mathrm{Y}_{2} \mathrm{O}_{3}$ & PS & $260-815$ & $122-305$ & $8-130 \mu \mathrm{m} \mathrm{Al} \mathrm{Al}_{3}$ & $20-90$ & Erosion & {$[22]$} \\
\hline $\mathrm{ZrO}_{2}-\mathrm{Y}_{2} \mathrm{O}_{3}-\mathrm{TiO}_{2}$ & PS & $260-815$ & $122-305$ & $8-130 \mu \mathrm{m} \mathrm{Al}_{2} \mathrm{O}_{3}$ & $20-90$ & Rates & {$[22]$} \\
\hline $\mathrm{CaO} \mathrm{TiO}_{2}$ & PS & $260-815$ & $122-305$ & $8-130 \mu \mathrm{m} \mathrm{Al}_{2} \mathrm{O}_{3}$ & $20-90$ & Quoted & [22] \\
\hline $\mathrm{Zro}_{2}-\mathrm{MgO}$ & PS & $260-815$ & $122-305$ & $8-130 \mu \mathrm{m} \mathrm{Al}_{2} \mathrm{O}_{3}$ & $20-90$ & “ & [22] \\
\hline $\mathrm{ZrO}_{2}-8 \mathrm{wt} \% \mathrm{Y}_{2} \mathrm{O}_{3}$ & PS & $260-815$ & $122-305$ & $8-130 \mu \mathrm{m} \mathrm{Al}_{2} \mathrm{O}_{3}$ & $20-90$ & “" & {$[12 ; 23]$} \\
\hline $\mathrm{ZrO}_{2}-8 \mathrm{wt} \% \mathrm{Y}_{2} \mathrm{O}_{3}$ & EB-PVD & $260-815$ & $122-305$ & $8-130 \mu \mathrm{m} \mathrm{Al}_{2} \mathrm{O}_{3}$ & $20-90$ & “ & {$[12 ; 23]$} \\
\hline $\mathrm{ZrO}_{2}-8 \mathrm{wt} \% \mathrm{Y}_{2} \mathrm{O}_{3}$ & PS & RT-960 & $50-400$ & $100 \mu \mathrm{m} \mathrm{Al}_{2} \mathrm{O}_{3}$ & $30-90$ & $210-322$ & {$[10]$} \\
\hline $\mathrm{ZrO}_{2}-8 \mathrm{wt} \% \mathrm{Y}_{2} \mathrm{O}_{3}$ & EB-PVD & RT-960 & $50-400$ & $100 \mu \mathrm{m} \mathrm{Al} \mathrm{O}_{3}$ & $30-90$ & $20-28.5$ & {$[10]$} \\
\hline $\mathrm{ZrO}_{2}-8 \mathrm{wt} \% \mathrm{Y}_{2} \mathrm{O}_{3}$ & PS & RT-960 & $50-400$ & $60 \mu \mathrm{m} \mathrm{Si0}{ }_{2}$ & $30-90$ & $49-540$ & [10] \\
\hline $\mathrm{ZrO}_{2}-8 \mathrm{wt} \% \mathrm{Y}_{2} \mathrm{O}_{3}$ & EB-PVD & RT-960 & $50-400$ & $60 \mu \mathrm{m} \mathrm{Si} 0_{2}$ & $30-90$ & $10-27$ & [10] \\
\hline $\mathrm{ZrO}_{2}-7 \mathrm{wt} \% \mathrm{Y}_{2} \mathrm{O}_{3}$ & PS & 1093 & 244 & $27 \mu \mathrm{m}$ & 30 & $3.8-152$ & [24] \\
\hline
\end{tabular}

Table 1: Summary of the erosion rates of TBCs under various conditions.

As can be seen from the above table, a broad range of erosion testing has been conducted on thermal barrier coatings, with the majority of tests being carried out on PS coatings. Most of the tests have used $\mathrm{Al}_{2} \mathrm{O}_{3}$ as the erodent, with some tests being duplicated using $\mathrm{SiO}_{2}$ as the erodent. Temperatures ranged from room temperature to $1600^{\circ} \mathrm{C}$ with the test velocities ranging from 30$400 \mathrm{~m} / \mathrm{s}$ at impact angle from $20-90^{\circ}$. Unfortunately, a fair number of the results are reported as relative erosion rates, making comparisons difficult.

From the work carried out by Tabakoff [23] and Nicholls [19] it appears that the erosion rate of the coatings increases linearly with velocity, following an equation of the form:

$$
\mathrm{E}=\mathrm{cV}
$$

Where $\mathrm{E}$ is the erosion rate in $\mathrm{g} / \mathrm{kg}, \mathrm{V}$ is the velocity in $\mathrm{m} / \mathrm{s}$, and the constant $\mathrm{c}$ varies for different erosion conditions as shown in the table below. 


\begin{tabular}{|l|l|l|l|l|}
\hline System & Erodent & c & Temp & Impact Angle \\
\hline EB-PVD & $\mathrm{Al}_{2} \mathrm{O}_{3}$ & 0.131 & Independent & $90^{\circ}$ \\
\hline PS & $\mathrm{Al}_{2} \mathrm{O}_{3}$ & 1.43 & Independent & $90^{\circ}$ \\
\hline EB-PVD & $\mathrm{SiO}_{2}$ & 0.102 & RT & $90^{\circ}$ \\
\hline PS & $\mathrm{SiO}_{2}$ & 0.735 & RT & $90^{\circ}$ \\
\hline
\end{tabular}

Table 2: Values for $\mathrm{c}$ at various conditions [19].

Using this information and their own results, which in some cases used exactly the same material as Tabakoff, Nicholls et al [19] were able to calculate the absolute erosion rates for Tabakoff's [23] work. The two sets of results correlate extremely well. Having examined both sets of results the following conclusions were made:

-Erosion does play a significant role in determining the life/durability of TBCs.

-Over the range of temperatures tested (RT to $910^{\circ} \mathrm{C}$ ) EB-PVD coatings are more erosion resistant than PS coatings, by as much as an order of magnitude under some conditions.

The difference in erosion rate of the two types of coating was attributed to different mechanisms operating, due to the differences in microstructure. With EB-PVD coatings, localised fracture was observed to occur in the near surface region of the columnar microstructure, while with the PS coatings, material removal was found to occur through the removal of whole splats, owing to poor intersplat cohesion.

\section{THE CONCEPT OF A COMPUTERISED EROSION MODEL}

Monte Carlo simulation techniques can be used to model the stochastic nature of the erosion process. Particle properties, material surface condition, and the local dynamic impact environment are individually considered. Using Monte Carlo methods discrete impact conditions are selected and the amount of damage is calculated per impact event. The erosion rate is the sum of all these damaging events. In applying such a model it is first necessary to determine the mechanism of material removal. Since, due to the microstructure of EB PVD TBCs, classical mechanisms proposed by Lawn et al and Tilly [16] [25;26]can not be used.

Nicholls and co-workers [27-30] have done significant work on the Monte Carlo modelling of erosion, looking specifically at the erosion of oxide scales at various temperatures. Although this work cannot be used to predict the erosion rate of TBCs, owing to the difference in erosion mechanisms, it does however provide the framework from which a TBC erosion model can be developed.

\section{THE ROLE OF TBC MICROSTRUCTURE}

When dealing with TBCs one has to consider two very distinctive and very different microstructures, depending on whether they were deposited via the EB PVD method or whether they were plasma sprayed. Due to their different microstructures they can not be treated in the same way as conventional engineering materials or indeed in the same way as each other. The very nature of the microstructure of these two processes necessitates the definition of two new erosion mechanisms. Or, at the very least, major modifications to classical erosion mechanisms. This paper, however, is only concerned with the erosion of EB PVD TBCs. 
The microstructure of EB PVD TBCs can be described as a tapered columnar structure, Figure 1, resulting from the three dimensional growth of the columns which can inhibit the growth of neighbouring columns.

It is this columnar microstructure of the EB PVD coatings, which gives them their high strain tolerance due to the fact that under mechanical load or thermal cycling the ceramic columns can move thus accommodating the strain [31]. This option is not available to the PS coatings, although research effort is focused on microcracking the splat network to improve the degree of strain tolerance.

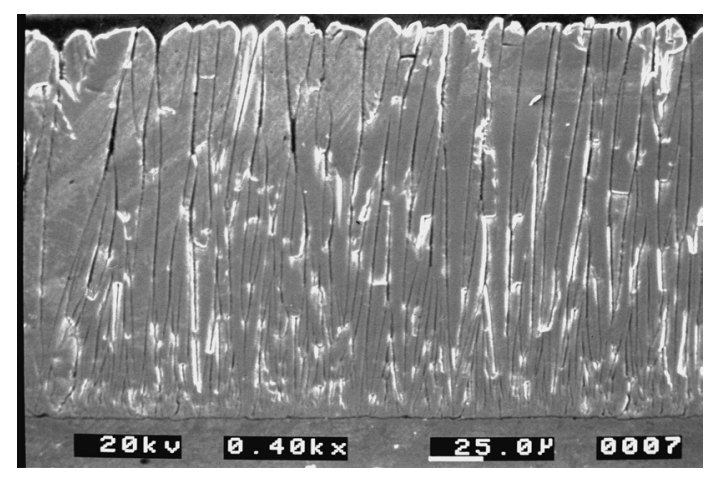

Figure 1: Micrograph showing the columnar microstructure of EB TBCs

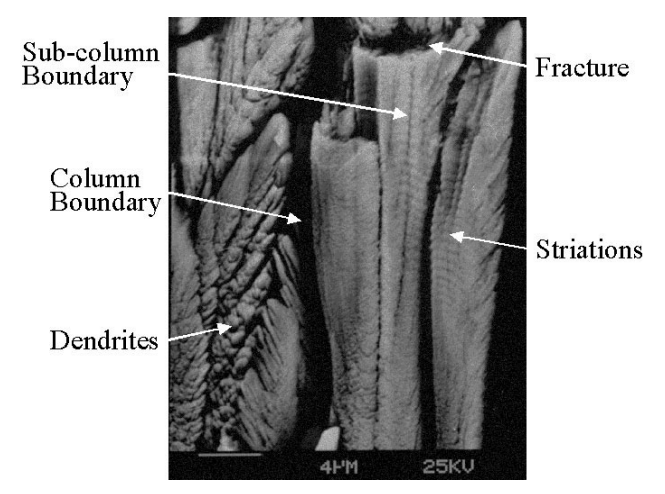

Figure 2: Micrograph of an EB PVD coating showing various microstructural features.

In a previous paper [32] the authors examined back scattered SEM micrographs of the cross section of EB PVD TBCs, and identified some microstructural features that could be important when trying to obtain a mechanistic understanding of erosion. These are illustrated in Figure 2. The most important of these features are the column and sub column boundaries and the dendritic structure at the major column boundaries, all of which can influence the erosion of the coatings.

\section{EROSION MECHANISMS OF EB PVD TBCS}

Due to the columnar morphology of TBCs, Hertzian ring cracks and cone cracks are highly unlikely to occur and the analysis of eroded samples shows no evidence of Hertzian type cracking. After studying the micrographs of the cross sections of eroded TBCs it became evident that there were a number of different fracture mechanisms operating during the erosion of TBCs. The different mechanisms appear to operate in different regions of the coating. The most important type of damage occurring during erosion is the cracking that occurs in the near surface region of the coating, the first $20 \mu \mathrm{m}$ of the coating. This is the region, which accounts for the majority of the material removal during the erosion process. In this region there appears to be two mechanisms operating one of which is similar to the median/lateral mechanism.

On initial loading of the impacted column a region of inelastic deformation is formed (possibly densification), this area is surrounded by a region of elastic deformation. On unloading of the sample the region of elastic deformation is prevented from relaxing as a result of the constraint provided by the region of inelastic deformation. This results in a tensile stress beneath the point of indentation, in the direction of column growth and can initiate cracks parallel to the surface, see Figure 3. 
It is assumed that the depth at which cracking will occur is directly related to the force of the impacting particle and the radius of that particle. Since these two factors will determine the size of the region of inelastic deformation, they influence the depth at which cracking will occur and hence determine the rate of material removal.

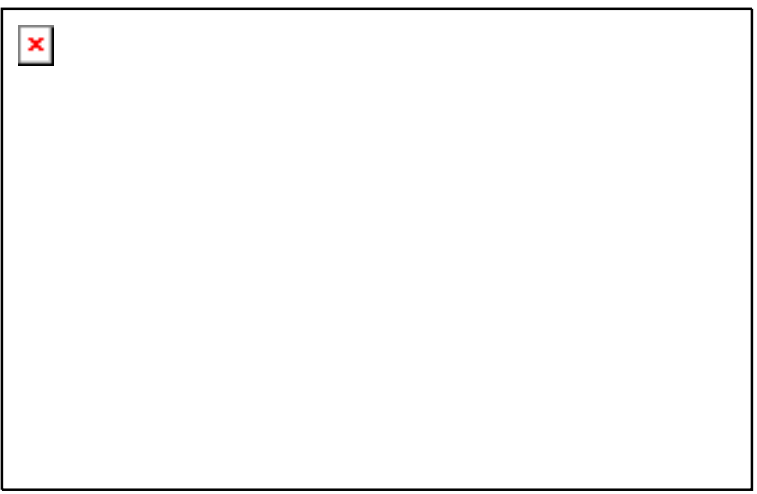

Figure 3: SEM Micrograph showing cracking caused by impact damage.

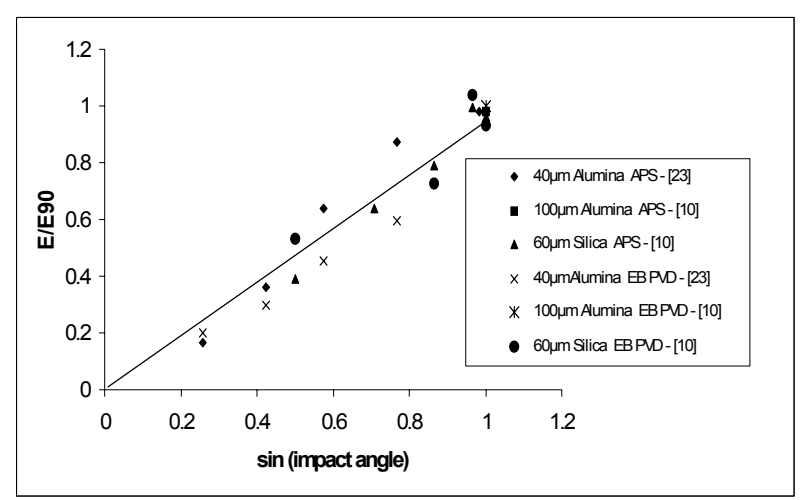

Figure 4: Plot of erosion rate vs. sin(impact angle) for EB PVD TBCs.

It was obvious from the micrographs of eroded EB PVD TBCs (Figure 3 is one example) that an accumulation of damage in the form of cracks is needed before material is removed. A single impact on an EB PVD TBCs will not necessarily result in material removal even though it might have fractured the column it impacted. This is attributed to the constraint of neighbouring columns 'holding' the fractured section in place. Only once a number of adjacent columns have been fractured can a subsequent impact result in material removal. When this does occur, the fractured sections of a number of columns will be removed together.

\section{DEVELOPING A COMPUTATIONAL EROSION MODEL FOR EB PVD TBCs}

One of the first things needed when modelling erosion is to determine the parameters controlling the erosion mechanism, which can be achieved by studying a combination of single impact and steady state erosion impacts for a given set of erosion conditions. Once the erosion mechanisms for different conditions/regimes have been identified and defined, erosion models can be developed to predict the erosion rates for these different conditions.

Using the information obtained from the literature and information from the single impact studies used to deduce the erosion mechanism, a first stage computer model has been developed (coded using Delphi, an object orientated programming version of Pascal) to calculate the erosion rates of EB PVD TBCs under solid particle impact conditions.

In order to facilitate visualising the interaction of the columns and the impacting particles it was assumed that the columns were all hexagonal in shape. The model comprises of 25 of these columns and 'wraps' around in a two-dimensional manner such that each column has six nearest neighbours (NN). A column and its six nearest neighbours need to be fractured before material removal occurs. However, it is possible that fewer impacts on the nearest neighbours are required before material removal occurs which would result in the model predicting a higher erosion rate. Figure 5 is a flow diagram for the current model, showing the sequences involved in determining the erosion rate. 


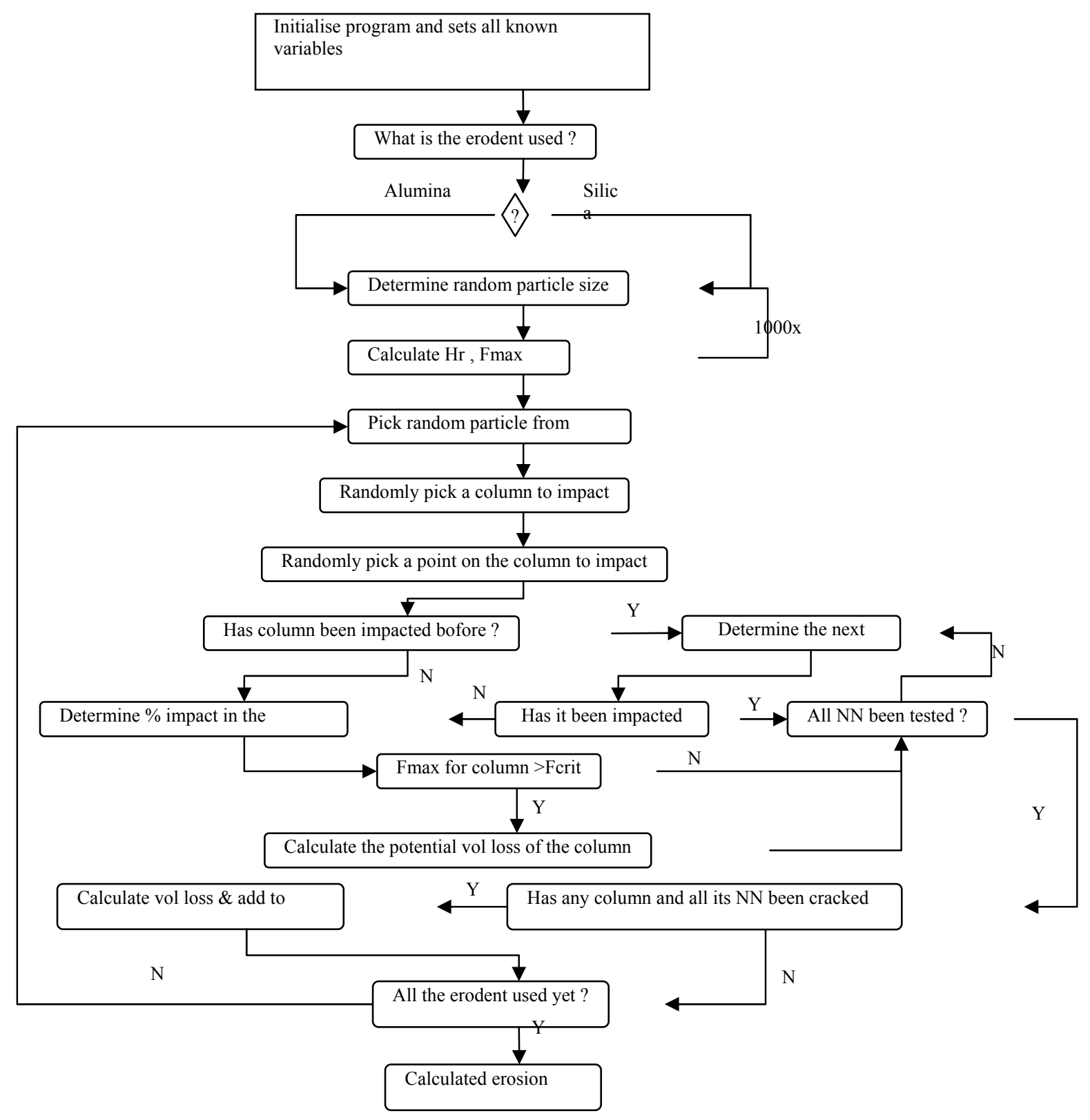

Figure 5: Flow diagram for the computer model. Where $\mathrm{Hr}$ is the Hertz contact radius, Fmax is the impact force and Fcrit the minimum force required to initiate cracking.

\subsection{Influence of impact angle}

The affect of impact angle on brittle erosion is well documented in the literature, although not mathematically modelled. For the case of EB PVD TBCs, after examining the reported erosion rates of TBCs under various conditions and impact angles, it appears as though there is a dependence of erosion rate on the sine of the impact angle, which is illustrated in Figure 4.

When eroding at glancing impact angles the velocity can be resolved into two components (vertical and horizontal). Only the vertical component of velocity contributes to the damage sustained an EB PVD thermal barrier coating. The horizontal component will not contribute to the cracking of the coating, however, it could contribute to the removal of columns that have already 
been damaged/cracked. Thus given that normal impacts occur at $90^{\circ}$, relative to the surface, then the vertical component of the resolved impact force will vary as the sine of the impact angle, as shown in Figure 4.

\subsection{Damage area per impact}

One question that analysing eroded samples can not answer is whether a single impact can cause damage to more than one column at a time. Initial calculations show that the Hertz contact footprint, when eroding at $140-300 \mathrm{~m} / \mathrm{s}$ using silica or alumina with a particle size of $100 \mu \mathrm{m}$ as the erodent, is of the same order of magnitude as the column size. The important factor here being the ratio between the Hertzian contact radius and the size of the column, which can be in excess of 2.5. This implies that when the Hertz radius is greater than the column diameter a single particle impact, even if it strikes in the middle of the column, will interact with more than one column. In order to determine whether one impact could cause damage to more that one column it is necessary to determine the percentage of the contact footprint that falls into the adjacent columns. This depends not only on the ratio of Hertz radius vs. column size but also on where in the column it impacts. Once this is known one can then calculate the relative stresses to which each column would be subjected and hence determine whether the columns will fracture or not. The first part of this work has been completed but has not yet been incorporated into the computerised model of the erosion process.

\section{MODEL PREDICTIONS}

This model is still in the development stage and a number of refinements need to be added before it is complete. However, it can be run and, in the case of silica as the erodent, currently yields a reasonable result.

The model was run under the same conditions as the experimental tests, which used silica with an average radius of $30 \mu \mathrm{m}$ as the erodent at a velocity of $170 \mathrm{~m} / \mathrm{s}$ at room temperature. There are a number of factors, which still need to be incorporated into the erosion model, which account for the differences between the results from the model and the experimental results. The current model is only looking at the scenario of the impacting particles interacting with only one column. In reality this is not the case and has been discussed in an earlier section.

\begin{tabular}{|l|l|l|}
\hline $\begin{array}{l}\text { Impact Angle } \\
\left({ }^{\circ}\right)\end{array}$ & $\begin{array}{l}\text { Erosion Rate }(\mathrm{g} / \mathrm{kg}) \\
\text { From Model }\end{array}$ & $\begin{array}{l}\text { Erosion Rate }(\mathrm{g} / \mathrm{kg}) \\
\text { From Literature }[10]\end{array}$ \\
\hline 90 & 9.5 & 17.5 \\
\hline 75 & 9.4 & 19.5 \\
\hline 60 & 9.13 & 13.8 \\
\hline 45 & 8.3 & $31.2^{*}$ \\
\hline 30 & 7.2 & 10 \\
\hline
\end{tabular}

Table 3: Table of results of Model compared to results from the literature.

* Acknowledged by the Authors as an unusually high result.

\section{CONCLUSIONS}

As a first stage approximation the computational erosion model gives acceptable results. The data fit within a factor of two, which is consistent with the idea that impacting particles may damage more than one column. A number of factors still have to be incorporated into the model in order 
to improve its accuracy. These include quantifying the number of columns damaged per impact, evaluating how many damaged columns are required to permit material removal and evaluating the role of particle shielding, which reduces the erosion rate under normal impact conditions.

\section{REFERENCES}

Cruse T.A, Stewart S.E., and Ortiz M., Transactions of the ASME, 110 (1988) 610-616.

Wu B.C., Chang E., Chang S.F. and C.H Chao, Thin Solid Films , 172 (1989) 185-196.

3 Sun J.H., Chang E., Wu B.C and Tsai C.H., Surface and Coatings Technology , 58 (1993) 93-99.

4 Nissley D.M., Thermal Barrier Coatings Workshop NASA Conference Publication 3312, (1995) 265-281. Jaslier Y. and Alperine S., AGARD Report 823 , (1998) 8. Novak R.C., NASA Conference Publication 3312, (1995) 153-166. Kaysser W.A., Peters M., Fritscher K. and Schulz U., AGARD Report 823, (1998) 9. Dorvaux J.M., Lavigne O., Mevrel R., Poulain M., Renollet Y. and Rio C., AGARD Report 823, (1998)

9 Dinwiddie R.B., Beecher S.C., Nagaraj B.A. and Moore C.S., NASA Conference Publication 3312, (1995) 167.

Nicholls J.R., Jaslier Y., and Rickerby D.S.. Erosion and Foreign Object Damage of Thermal Barrier Coatings. 4th international Colloquia on Corrosion and Protection of Materials at High Temperatures. 96.

Nicholls J.R., Lawson K.J., Rickerby D.S. and Morrell P., Thermal Barrier Coatings, Agard Report 823 (1998a) Paper 6.

Rhys-Jones T. and Toriz F.C., High Temperature Technology, 7 (1989) 73-81.

Tabakoff W. and Shanov V., Surface and Coatings Technology , 76-77 (1995) 75-80.

Davis A.G., Boone D.H. and Levy A.V., Wear, 110 (1986) 101-116.

Ruff A.W. and Wiederhorn S.M.. Treatise of Materials Science. C.M Preece. Treatise of Materials Science. 16, 69-. 79. Academic Press.

Lawn B.R. and Fuller E.R., Journal of Materials Science , 10 (1975a) 2016-2024.

Nicholls J.R., Jaslier Y. and Rickerby D.S., Materials at High Temperature, 15 (1998b) 15-22. 278-285.

Lawn B.R. and Swain M.V., Journal of Materials Science , 10 (1975b) 113-122.

Tilly G.P., Treatise on Materials Science \& Technology, 13 (1979) 287-319.

Stephenson D.J. and Nicholls J.R., Corrosion Science, 35 (1993) 1015-1026.

Stephenson D.J. and Nicholls J.R., Wear, 186-187 (1995) 284-290.

Nicholls J.R. and Stephenson D.J., Wear, 186-187 (1995) 64-77.

Handcock P., Nicholls J.R. and Stephenson D.J., Surface and Coatings Technology, 32 (1987) 285-304.

31 Evans A.G., Journal of the American Ceramic Society, 56 (1973) 405-409.

32 Wellman R.G. and Nicholls J.R., Wear, (to be published) 